\title{
Lyme disease: clinical diagnosis and treatment
}

\author{
Hatchette $\mathrm{TF}^{1,2,3^{*}}$, Davis $\mathrm{I}^{1,2}$ and Johnston $\mathrm{BL}^{2}$ \\ Department of Pathology and Laboratory Medicine, Capital District Health Authority (CDHA), Halifax, Nova Scotia \\ Department of Medicine, CDHA and Dalhousie University, Halifax, Nova Scotia \\ 3 Department of Pathology, Dalhousie University, Halifax, Nova Scotia \\ * Corresponding author: todd.hatchette@cdha.nshealth.ca
}

\begin{abstract}
Background: Lyme disease is an emerging zoonotic infection in Canada. As the Ixodes tick expands its range, more Canadians will be exposed to Borrelia burgdorferi, the bacterium that causes Lyme disease.

Objective: To review the clinical diagnosis and treatment of Lyme disease for front-line clinicians.

Methods: A literature search using PubMed and restricted to articles published in English between 1977 and 2014.

Results: Individuals in Lyme-endemic areas are at greatest risk, but not all tick bites transmit Lyme disease. The diagnosis is predominantly clinical. Patients with Lyme disease may present with early disease that is characterized by a "bull's eye rash", fever and myalgias or with early disseminated disease that can manifest with arthralgias, cardiac conduction abnormalities or neurologic symptoms. Late Lyme disease in North America typically manifests with oligoarticular arthritis but can present with a subacute encephalopathy. Antibiotic treatment is effective against Lyme disease and works best when given early in the infection. Prophylaxis with doxycyline may be indicated in certain circumstances. While a minority of patients may have persistent symptoms, evidence does not demonstrate that prolonged courses of antibiotics improve outcome.

Conclusion: Clinicians need to be aware of the signs and symptoms of Lyme disease. Knowing the regions where Borrelia infection is endemic in North America is important for recognizing patients at risk and informing the need for treatment.
\end{abstract}

\section{Introduction}

Lyme disease is the most common vector-borne zoonosis in North America, where it is estimated that each year more than 300,000 individuals in the United States (US) are infected by Borrelia burgdorferi, the bacterium that causes Lyme disease(1). Data from Canada are sparse, as Lyme disease only became nationally reportable in 2009. The number of reported infections in Canada in 2012 was 315 , which is likely an underestimate and includes cases that are the result of infections acquired during travel to other endemic regions, such as Europe (2-4).

The range of Ixodes ticks, the vector for Borrelia, has expanded greatly over the last 20 years, making Lyme disease an emerging infection in Canada. Ixodes ticks have been identified in British Columbia, southeastern Manitoba, southern and eastern Ontario, and specific areas in New Brunswick, Nova Scotia and Quebec $(4,5)$. As the Ixodes tick expands its range, more Canadians will be exposed to $B$. burgdorferi, and clinicians will need the expertise to manage tick bites and diagnose and treat Lyme disease.

Awareness of the extent of local Lyme disease, early detection and treatment are important for managing this emerging infection. The objective of this article is to review the clinical diagnosis and treatment of $B$. burgdorferi infection for the front-line clinician. 


\section{Methods}

A literature search was done using PubMed and restricted to articles published in English between 1977 and 2014. The following search terms were used: Lyme disease and treatment, Lyme disease and arthritis, Lyme disease and clinical presentation, Lyme disease ticks and risks, Lyme disease and pregnancy, neuroborreliosis, chronic Lyme OR post-Lyme syndrome AND treatment (clinical trials). Abstracts were reviewed for clinically relevant articles, and additional references were obtained from the articles identified in the initial search. Although there are different strains of Borrelia in North America and Europe, which are associated with overlapping but distinct clinical presentations, this review will focus on the clinical manifestations that are common to Canada. It does not describe the various aspects of diagnostic testing, which is reviewed in a companion paper (6).

\section{Findings}

\section{Who is at risk of Lyme disease and why?}

An individual must first be bitten by a tick that is infected with $B$. burgdorferi for infection to occur. While infected ticks can be sporadically deposited in different regions in Canada by migratory birds, the risk of getting Lyme disease is greatest in an area where the ticks are persistently present or endemic, and the risk depends on the proportion of ticks that are infected. Even in areas where the ticks have become endemic, the proportion infected by this spirochete varies and is evolving. Clinicians may want to check with their local public health departments to understand where the current Lyme endemic areas are within their jurisdiction. It is important to obtain a thorough travel history from the patient, as Lyme disease is endemic in other areas of North America and Europe, and travel-related Lyme disease accounts for a proportion of the documented cases in Canada. It is also important to relay this travel history or suspicion of European Borrelia infection to the diagnostic laboratory, as the confirmatory testing for North American and European Borrelia strains differs.

\section{What is the risk of Lyme after a tick bite?}

While studies are limited in numbers and size, data from the US and Europe suggest that the risk of acquiring Lyme disease, even after a bite from an infected tick, is small - in the range of $<1 \%$ to $6 \%$ (7). In studies that have examined the efficacy of antibiotic prophylaxis in persons presenting with a tick bite in Lyme-endemic areas (where the prevalence of $B$. burgdorferi in ticks ranged from $15 \%$ to $50 \%$ ), the rate of infection among those who received placebo ranged from $1.1 \%$ to $3.4 \%(8-11)$. These rates are consistent with a prospective study of patients bitten by ticks in a Lyme-endemic area of New York State, where infection developed in 3.7\% of those bitten by a tick (12).

The risk of infection following a tick bite is related to how long the tick has been attached and is explained by the Borrelia life cycle in the tick. The spirochete first has to migrate from the tick's gut to its salivary glands before it can be injected into the human through the bite. In order to do this, the bacterium must undergo antigenic change to its outer coat that favours human infection (13-16). This process takes about 36 hours (14). If the tick is removed during this time frame, infection is almost always prevented. In an antibiotic prophylaxis trial in the US, no study participants receiving placebo or prophylaxis were infected if the tick fed for less than 72 hours (11). This is further supported by data from another prospective study in an endemic region, in which participants were at greatest risk of infection if the tick had been attached for more than 72 hours (12).

\section{Who should receive prophylaxis after a tick bite?}

There are a number of factors that require consideration when deciding whether to offer prophylaxis after a tick bite (Table 1). All of the prophylaxis trials have been conducted in regions that would be considered hyperendemic for Lyme disease, where the burden of infection in ticks is $>20 \%$ and where the antibiotics were administered within 72 hours of removing the tick (8-11). An early meta-analysis of antibiotics for prophylaxis of Lyme disease reported a pooled infection rate in those who received placebo of $1.4 \%$, compared with $0 \%$ for those receiving an antibiotic (17). Each of the included trials was small and failed to show any significant effect of prophylaxis, as the incidence of infection in those taking placebo was low (8-10). A subsequent randomized placebo controlled trial showed that a single dose of doxycycline could reduce the rate of Lyme disease (11). 
Table 1. Criteria and recommended prophylaxis after a tick bite (19)

\begin{tabular}{|c|c|c|}
\hline \multirow[t]{4}{*}{$\begin{array}{l}\text { Criteria for } \\
\text { prophylaxis* }\end{array}$} & \multicolumn{2}{|c|}{$\begin{array}{l}\text { 1. The attached tick can be reliably identified as an I. scapularis (deer/blacklegged) tick } \\
\text { that is estimated to have been attached for }>36 \mathrm{~h} \text { on the basis of the degree of } \\
\text { engorgement or by certainty about the time of tick acquisition. }\end{array}$} \\
\hline & \multicolumn{2}{|c|}{ 2. Prophylaxis can be started within $72 \mathrm{~h}$ of tick removal. } \\
\hline & \multicolumn{2}{|c|}{$\begin{array}{l}\text { 3. The local rate of } B \text {. burgdorferi infection in ticks is }>20 \% \text { (check with local public } \\
\text { health). }\end{array}$} \\
\hline & \multicolumn{2}{|c|}{ 4. Doxycycline is not contraindicated. } \\
\hline \multirow[t]{2}{*}{$\begin{array}{l}\text { Recommended } \\
\text { prophylaxis }\end{array}$} & $\begin{array}{l}\text { Adults and children } \\
>8 \text { years of age }\end{array}$ & $\begin{array}{l}\text { Single } 200 \mathrm{mg} \text { dose of doxycycline given orally }(4.4 \mathrm{mg} / \mathrm{kg} \text { for } \\
\text { patients }<45 \mathrm{~kg})\end{array}$ \\
\hline & $\begin{array}{l}\text { Children }<8 \text { years } \\
\text { of age and } \\
\text { pregnancy }\end{array}$ & Not recommended \\
\hline
\end{tabular}

An updated systematic review and meta-analysis suggested that, to prevent one case of Lyme disease, prophylaxis of 49 cases would be needed (18). Patients in whom infection developed were successfully treated without any long-term sequelae. Given that there were relatively few infections in each of the studies and that these were successfully treated, the use of antimicrobial prophylaxis must be considered in the context of potential side effects, which were reported but were not severe.

\section{How do patients with Lyme disease present and how are they treated?}

Although patients with $B$ burgdorferi infection can be asymptomatic, most cases of Lyme disease present as one of three stages, which may occur sequentially if an earlier stage was untreated: early localized disease (usually $<30$ days from exposure), early disseminated disease ( $<3$ months after exposure) and late disseminated disease (> 3 months after exposure) (Table 2).

Table 2. Clinical manifestations of Lyme disease $(19,24,39)$

\begin{tabular}{lll}
\hline Stage & System & Manifestation \\
\hline $\begin{array}{l}\text { Early localized disease } \\
(<30 \text { days })^{*}\end{array}$ & Skin & $\begin{array}{l}\text { Erythema migrans (note: must be }>5 \mathrm{~cm} \text { in } \\
\text { diameter, painless and slowly expanding) }\end{array}$ \\
& Systemic & Fever \\
& & Arthralgias \\
\hline $\begin{array}{l}\text { Early disseminated disease } \\
(<3 \text { months })^{*}\end{array}$ & Headache \\
& Skin & Multiple erythema migrans \\
& & Fever \\
& & Arthralgias \\
& Heart & Headache \\
& & Lymphadenophathy \\
& Atrioventricular block \\
& Tachyarrhythmias \\
& CNS & Myopericarditis \\
& Myocardial dysfunction \\
& Aseptic meningitis \\
& Cranial neuropathy (especially facial nerve palsy)
\end{tabular}




\begin{tabular}{lll}
\hline Stage & System & Manifestation \\
\hline & Ocular & Conjunctivitis (rare) \\
\hline Late disseminated disease & MSK & Oligoarticular arthritis \\
$(>3 \text { months })^{*}$ & CNS & Encephalopathy \\
& & Axonal polyradiculoneuropathy \\
& & Chronic encephalomyelitis \\
\hline
\end{tabular}

\footnotetext{
* Note: While there may be exceptions, these time frames provide clinicians with a general guide on when the different manifestations tend to occur.

CNS = central nervous system.

MSK = musculoskeletal.
}

The treatment of Lyme disease depends on the stage and organ system involved and is summarized in a clinical practice guideline that has been developed by the Infectious Diseases Society of America (IDSA) (Table 3) (19). The clinical presentation and some of the literature that supports those treatment recommendations are summarized in the sections that follow.

Table3. Infectious Disease Society of America guidelines for the treatment of Lyme disease (19)*

\begin{tabular}{|c|c|c|}
\hline \multirow[t]{5}{*}{$\begin{array}{l}\text { Treatment of adults and } \\
\text { children older than } 8 \text { years } \\
\text { with Lyme disease }\end{array}$} & $\begin{array}{l}\text { Erythema migrans or early } \\
\text { disseminated disease, } \\
\text { including Bell's palsy, but } \\
\text { without other CNS } \\
\text { involvement }\end{array}$ & $\begin{array}{l}\text { - Doxycycline } 100 \mathrm{mg} \text { po bid x 14-21 days } \\
\text { (contraindicated in pregnancy) } \\
\text { - Amoxicillin } 500 \mathrm{mg} \text { po tid x 14-21 days } \\
\text { - Cefuroxime } 500 \mathrm{mg} \text { po bid x 14-21 days }\end{array}$ \\
\hline & $\begin{array}{l}\text { Early Lyme with CNS } \\
\text { involvement }\end{array}$ & $\begin{array}{l}\text { - Ceftriaxone } 2 \mathrm{~g} \text { IV once daily } \times 14-28 \text { days } \\
\text { - Pen G } 4 \times 10^{6} \text { units IV q } 4 \mathrm{~h} \times 14-28 \text { days } \\
\text { - Doxycycline } 100-200 \mathrm{mg} \text { po bid } \times 28 \text { days } \\
\text { (alternative if others not possible) }\end{array}$ \\
\hline & Early Lyme with carditis & $\begin{array}{l}\text { - Same treatment as early Lyme with CNS } \\
\text { involvement, but use IV initially with high grade heart } \\
\text { block or if admission to hospital is necessary. }\end{array}$ \\
\hline & $\begin{array}{l}\text { Late Lyme without CNS } \\
\text { involvement }^{\star *}\end{array}$ & $\begin{array}{l}\text { - Doxycycline } 100 \mathrm{mg} \text { po bid } \times 28 \text { days } \\
\text { - Amoxicillin } 500 \mathrm{mg} \text { po tid } \times 28 \text { days } \\
\text { - Cefuroxime } 500 \mathrm{mg} \text { po bid } \times 28 \text { days }\end{array}$ \\
\hline & $\begin{array}{l}\text { Late Lyme with CNS } \\
\text { involvement (late } \\
\text { neuroborreliosis) }\end{array}$ & $\begin{array}{l}\text { - Ceftriaxone } 2 \text { g IV once daily x 14-28 days } \\
\text { - Pen G } 4 \times 10^{6} \text { units IV q } 4 \text { h x 14-28 days }\end{array}$ \\
\hline \multirow[t]{3}{*}{$\begin{array}{l}\text { Treatment of children } 8 \text { years } \\
\text { or younger with Lyme disease }\end{array}$} & Early localized disease & $\begin{array}{l}\text { - Amoxicillin } 30 \mathrm{mg} / \mathrm{kg} \text { per day, orally, divided into } \\
\text { three doses (max } 1.5 \mathrm{~g} / \text { day) for } 14-21 \text { days } \\
\text { - For children allergic to penicillin, cefuroxime } 30 \\
\text { mg/kg per day, orally, in two divided doses } \\
\text { (maximum } 1 \mathrm{~g} / \text { day) for } 14-21 \text { days }\end{array}$ \\
\hline & $\begin{array}{l}\text { Early disseminated and late } \\
\text { disease: } \\
\text { multiple erythema migrans }\end{array}$ & - Oral treatment as the above for 21 days \\
\hline & $\begin{array}{l}\text { Early disseminated and late } \\
\text { disease: }\end{array}$ & - Oral treatment as the above for 21 days \\
\hline
\end{tabular}




\begin{tabular}{l|l}
$\begin{array}{l}\text { isolated facial palsy and first } \\
\text { episodes of arthritis }\end{array}$ & \\
\hline $\begin{array}{l}\text { Early disseminated and late } \\
\text { disease: }\end{array}$ & - Ceftriaxone or penicillin IV at pediatric dosing \\
persistent/recurrent arthritis, \\
carditis and \\
meningitis/encephalitis
\end{tabular}

*** These recommendations are off-label, evidence-based best practices.

Recurrent or persistent joint swelling - repeat 4 week course of oral antibiotic as above. Use of IV ceftriaxone should be reserved for relapse or persistent joint swelling without improvement with oral treatment.

CNS = central nervous system.

\section{Asymptomatic infection}

Approximately $1.6 \%-7 \%$ of infected individuals may have asymptomatic infection $(7,20)$. The prognosis for patients with asymptomatic infection is generally good. Within a large vaccine study conducted in 10 US states where Lyme is endemic, asymptomatic infections were documented in $6 \%(15 / 269)$ of study participants. While the majority of study participants received treatment when the seroconversion had been documented, only 1 of 8 who did not receive treatment went on to show arthritis over the 12 months after seroconversion (20). Although the follow-up period was relatively short, these data support the notion that asymptomatic infection does not require treatment, and disease will ultimately declare itself if infection persists.

\section{Early localized disease ( $<30$ days)}

Early disease usually presents as an acute illness characterized by fever, headache and myalgia with the presence of a single, localized skin lesion known as erythema migrans (EM). This characteristic skin eruption is present in approximately $80 \%$ of patients with early disease and will resolve without antibiotic treatment over a median of 28 days $(21,22)$. While most patients will present with erythema migrans within seven days of the initial tick bite, the incubation period can vary between 3 and 30 days (23). The skin lesion is characteristically an annular erythematous lesion $>5 \mathrm{~cm}$ in diameter that slowly increases in size and is usually painless and nonpruritic. The lesion sometimes develops central clearing, but it can be more homogenously erythematous (19, $23,24)$. It is important to note that many people can have a reaction to the tick saliva and show a localized reaction resembling erythema migrans. However, unlike erythema migrans this reaction often develops within the first three days of the bite, is $5 \mathrm{~cm}$ or less in diameter and does not expand.

Erythema migrans can be subtle or even go unnoticed, particularly if the bite was in an area that is difficult for the patient to see, such as behind the knee. Diagnostic testing is insensitive at this stage and not recommended in a patient who has links to an endemic area (6).

Treatment: Several clinical trials conducted in the US $(23,25-28)$ and Europe (29-31) has informed the antimicrobial treatment of early Lyme disease. In these trials, individuals with a clinical diagnosis of erythema migrans were randomly assigned to one of several treatment options. The agents used included amoxicillin, penicillin, ceftriaxone, a macrolide (erythromycin or azithromycin) and a tetracycline or doxycycline in somewhat varying doses and for varying lengths of times. Azithromycin therapy was given for 5 or 10 days, beta-lactams were given for 10-30 days, and tetracycline/doxycycline was given for 10, 14 or 20-21 days. Follow-up frequently lasted for several months after completion of therapy, and patients were monitored for complete and partial resolution of symptoms, treatment failure and late manifestations of illness that were considered either minor or major.

The studies found similar efficacy for amoxicillin, azithromycin, cefuroxime and doxycycline independent of the dose and duration of therapy. The one trial that included erythromycin showed it to be less effective than penicillin and tetracycline. A large retrospective cohort study of 607 patients confirmed these findings, $99 \%$ of patients with early local or disseminated Lyme remaining treatment-failure free at two years whether treated for $\leq$ 10 days, $11-15$ days or $>15$ days (32). One study that looked specifically at early disseminated Lyme disease compared ceftriaxone $2 \mathrm{~g}$ daily for 2 weeks with doxycycline $100 \mathrm{mg}$ twice daily for 3 weeks (33). Clinical cure was similar for the two (85\% for ceftriaxone and $88 \%$ for the doxycycline), with 14\% (doxycycline) and $27 \%$ 
(ceftriaxone) of patients having residual symptoms, usually mild arthralgias and fatigue, at nine months after completing treatment.

Prognosis: Both clinical trials $(23,25-31)$ and observational studies $(32,34-36)$ provide information about the prognosis for treated early Lyme disease. With the currently recommended therapies, greater than $80 \%$ of patients will have complete resolution of symptoms at long-term follow-up. While it is not unusual for individuals to have symptoms such as fatigue and arthralgias after treatment for Lyme, most studies reported either no or few $(<5 \%)$ late manifestations of disseminated Lyme.

To determine whether patients who had early Lyme disease are more likely to have persistent symptoms after their acute infection, investigators in Slovenia compared a cohort of patients treated for erythema migrans with a control group of individuals who did not have Lyme disease (36). They found that the frequency of new or increased symptoms in patients with this condition did not exceed the frequency of such symptoms in the control group. At 12 months, only $2.2 \%$ of Lyme disease patients reported new or increased symptoms, and in none of the patients were the symptoms disabling. These findings are similar to those of a study done in the US involving patients with and without Lyme disease from 1984 to 1991 (37). The frequency of new symptoms and increased difficulties with daily activities were similar in the two groups, those with Lyme disease and age-matched controls without Lyme disease.

In summary, the evidence from these studies suggests that although patients with Lyme may have symptoms that persist or appear after treatment is complete, the frequency of those symptoms is comparable with what one would see in individuals who do not have Lyme disease.

\section{Early disseminated Lyme disease ( $<3$ months)}

Early disease may be followed by disseminated disease, with the development of multiple secondary annular lesions and multisystem and intermittent cardiac, neurological, ocular or articular manifestations. The development of multiple secondary annular lesions and systemic symptoms, including fever, arthralgias, headache and lymphadenopathy, usually occurs within several weeks of the localized erythema migrans (38). In one early study, half of the patients presenting with this condition went on to show multiple erythema migrans lesions (38).

The other manifestations of early disseminated infection, such as Lyme carditis and neurologic infection (known as neuroborreliosis), tend to occur weeks to months after initial infection (38). Patients with Lyme carditis can present with conduction abnormalities, tachyarrhythmias, myopericarditis or myocardial dysfunction (39). The most common presentation is atrioventricular block ranging from first to third degree heart block, often requiring temporary pacing. Carditis usual occurs within two months of the presenting erythema migrans, but a history of the condition is not always present.

Treatment is effective, and carditis is rarely fatal (40). While earlier data showed that carditis developed in up to $10 \%$ of patients with untreated Lyme (39), recent data suggest that rates are much lower; this may be due to improved recognition of Borrelia infection and effective treatment (19). US data from 1996 to 2006 suggest that only $0.8 \%$ of patients reported to have Lyme disease have conduction abnormalities (41). Physicians should think of Lyme as a cause of unexplained conduction abnormalities in patients who have recently been to a Lymeendemic area. However, in the absence of a history of erythema migrans, the presentation is too non-specific to warrant empiric treatment without serological confirmation (19).

Neuroborreliosis has a clinical spectrum that can include meningitis, facial paralysis, motor or sensory radiculopathy, and cognitive symptoms. In North America, neuroborreliosis commonly presents with cranial nerve involvement (especially Bell's palsy), with or without aseptic meningitis. Symptoms can appear anywhere from two to eight weeks after erythema migrans (42). Lyme disease can be responsible for Bell's palsy in $10 \%-$ $50 \%$ of children and adults in Lyme-endemic areas and can be bilateral in up to $23 \%$ of patients (43-47). Clinicians should suspect Lyme disease as the cause of facial palsy when it occurs in Lyme-endemic areas during the tick season, is associated with headache and other non-cranial nerve neurologic findings, including papilledema, or is bilateral $(44,47-50)$.

In regions where Lyme is endemic, it can be challenging to differentiate early neuroborreliosis from other causes of central nervous system infection. The cerebrospinal fluid is usually abnormal, with a white cell count that is 
elevated to levels similar to those of patients presenting with viral meningitis $(48,51)$. However, compared with other causes of aseptic meningitis, patients with Lyme meningitis are less likely to have fever and more likely to have a higher preponderance of mononuclear cells (total percentage of monocytes and lymphocytes) in the cerebrospinal fluid, a longer duration of headache, and cranial nerve involvement $(48,52,53)$.

The rule of sevens: A clinical prediction rule has been developed to help stratify the likelihood of Lyme-related meningitis in children. Children are unlikely to have Lyme-related meningitis if they have all of the following: headache for fewer than seven days, less than $70 \%$ mononuclear cells in their cerebrospinal fluid and absence of a seventh nerve palsy. This "rule of $7 \mathrm{~s}$ " has $96 \%$ sensitivity and $95 \%$ specificity for distinguishing aseptic meningitis from Lyme neuroborreliosis. On the basis of the rule of $7 \mathrm{~s}$, patients who lack these features can be managed conservatively while Lyme serological results are pending $(53,54)$.

Treatment: A study done in the US in the early 1990s of patients with disseminated Lyme disease(without meningitis) compared ceftriaxone $2 \mathrm{~g}$ daily for 14 days with doxycycline $100 \mathrm{mg}$ twice daily for 21 days (33). The cure rate was similar for the two regimens ( $88 \%$ for ceftriaxone and $85 \%$ for doxycycline), $27 \%$ of ceftriaxonetreated patients and $14 \%$ of doxycycline- treated patients having residual symptoms at the end of treatment.

In a large series of 101 adults with Lyme-related Bell's palsy, the palsy resolved completely in more than $86 \%$ at a median time of 26 days (range 1-270 days) despite the fact that only $36 \%$ had received antibiotic treatment. Fifteen percent had mild residual weakness, and only one person had a severe deficit. Patients with residual dysfunction were more likely to have bilateral disease (43).

The prognosis in children is equally good. In a cohort study, $94 \%$ of children treated with antibiotics were asymptomatic four weeks after treatment. All but one patient had resolution of symptoms by six months, and no children had evidence of chronic disease two years later (34). In 43 children who presented with Bell's palsy attributable to Lyme disease, most felt that they were cured, and there was no difference in the daily activities of infected children compared with those of a non-infected group (55). These studies in patients with Lyme neuroborreliosis highlight the importance of early recognition and treatment in order to improve response to treatment. At the same time, it was demonstrated that a prolonged course of amoxicillin given orally after a three week course of intravenous ceftriaxone did not alter outcome as compared with placebo (56).

\section{Late Lyme disease (> 3 months)}

If left untreated, Lyme disease can evolve into late disease, which presents with persistent arthritis and/or persistent neuroborreliosis. The different strains of Borrelia in North America and Europe are associated with overlapping but distinct clinical presentations. In Europe, late Lyme disease presents with dermatologic syndromes that are rare in North America, including acrodermatitis chronica atrophicans and lymphocytoma cutis (24). In North America, arthritis is a much more common manifestation of late Lyme disease, whereas in Europe neuroborrelia is more commonly seen and presents as a chronic encephalitis or painful radiculopathy called Bannwarth's syndrome in up to $86 \%$ of cases (57).

If European Lyme disease is suspected on the basis of the clinical presentation and the patient's travel history, the laboratory should be notified to ensure that the appropriate serological test can be used, as the confirmation tests for North American and European Borrelia are different. A more detailed comparison of the differences between North American and European Lyme disease has been provided by Hengge and colleagues (24).

\section{Late Lyme arthritis}

In North America, up to $60 \%$ of untreated Lyme disease cases show monoarticular or oligoarticular arthritis, usually involving the knees, with other joints such as the ankle, elbow and wrist less commonly affected (58-60). In one study, all patients with late Lyme arthritis had symptoms appear within two years of infection. In 14 of 16 patients with untreated Lyme-related facial nerve palsies arthritis ultimately developed (61). Remembering a tick bite has not been a helpful feature in diagnosing Lyme arthritis, as up to $84 \%$ of cases did not recall exposure to a tick $(32,62)$.

Lyme disease serology is very sensitive and specific for the diagnosis of Lyme arthritis, and a negative test essentially rules out infection (6). However, the results of Lyme disease testing can take time, and because the presentation can mimic septic arthritis, which requires immediate treatment, it is important to try and differentiate the two. 
Three studies have attempted to develop a clinical prediction model to distinguish Lyme arthritis from septic arthritis in Lyme-endemic areas. Although there is an overlap between the two entities, Lyme arthritis tends to involve the knees preferentially, is less frequently accompanied by fever and local signs of inflammation, and in general has lower inflammatory markers (62-64). One study found refusal to weight bear as the strongest predictor septic arthritis compared with Lyme disease (63). Another study in children found that an erythrocyte sedimentation rate of $<40 \mathrm{~mm} /$ hour and a peripheral white blood cell count $<10 \times 10^{3} \mathrm{cells} / \mathrm{mm}^{3}$ could effectively rule out septic arthritis (64). While the synovial fluid is inflammatory with elevated leukocyte counts, there is overlap with septic arthritis, and the cell count can range from $1,700 \times 10^{3}$ cells $/ \mu \mathrm{L}$ to $>100,000 \times 10^{3}$ cells $/ \mu \mathrm{L}$, predominantly polymorphonuclear cells $(58,60,63)$. In one review, children with Lyme disease had higher inflammatory markers than adults (60).

Up to $10 \%$ of patients will have evidence of synovitis six months after treatment for Lyme arthritis, termed antibiotic refractory Lyme arthritis (65). Currently, the only recommendation for the use of the polymerase chain reaction (PCR) to detect Borrelia DNA in the diagnosis of Lyme disease has been in patients with persistent synovial swelling, to determine whether retreatment is necessary (19). However, the significance of a positive test result after primary treatment is unclear. There are data to suggest that any Borrelia detected are not viable, calling into question whether there really is persistent infection in these patients (66).

Late Lyme arthritis treatment: There are few studies that have examined the treatment of late Lyme arthritis. Two studies $(67,68)$ comparing penicillin or ceftriaxone with placebo in late Lyme arthritis in adults found benefit with antibiotic therapy, but the cure rate was still $<50 \%$, although better with ceftriaxone than penicillin. A European randomized trial comparing penicillin and ceftriaxone, both intravenously for 10 days, in patients 13 years of age and older demonstrated a symptom remission rate of $87.9 \%$ for ceftriaxone and $61.3 \%$ for penicillin. Finally, a study involving children and adults with late Lyme in the US in the mid-2000s (69) found that 28 days $(70 \%$ cure) of ceftriaxone had no advantage over 14 days ( $76 \%$ cure) in terms of clinical cure and was associated with more treatment discontinuations due to adverse events. In some series up to $25 \%$ of children and $50 \%$ of adults required a second course of antibiotics because of refractory arthritis symptoms. Those who went on to show refractory arthritis were successfully treated with nonsteroidal anti-inflammatories, steroid injections or disease-modifying drugs. None developed long-term sequelae $(59,60)$.

\section{Late neuroborreliosis}

The most common manifestation of neuroborreliosis in North America is subacute encephalopathy with subtle cognitive changes, whereas a chronic encephalomyelitis characterized by spastic paraparesis and cognitive impairment is more common in Europe $(24,70)$. In one case series of 37 American patients, neuroborreliosis manifested approximately two years after erythema migrans as subacute encephalopathy; axonal polyradiculoneuropathy with objective sensory and electromyography abnormalities; or leukoencephalitis; or a combination of the three (42). It is important to note that the patients had objective findings and serological evidence of infection.

Late neuroborreliosis treatment: All of the original studies examining treatment of neuroborreliosis that were identified in our search were undertaken in Europe $(56,71-77)$. While the clinical manifestations of Lyme disease are somewhat different in Europe and North America, presumably the treatment principles are similar. These different studies compared a variety of different drugs, treatment doses and treatment durations. Generally, however, the comparators were intravenous ceftriaxone/cefotaxime, intravenous penicillin or oral doxycycline ( $200 \mathrm{mg}-400 \mathrm{mg}$ daily) for anywhere between 10 days and 3 weeks. Patients had a mix of early and late neurological disease, and follow-up was often for several months after treatment had stopped. The treatment success was comparable for the different treatment arms, but the dose of doxycycline was higher in some of these studies than that used for early Lyme disease. Treatment success was generally higher than $80 \%$ but as low as 33\% in one group of patients with late Lyme neuroborreliosis who received ceftriaxone for two weeks.

\section{What is the prognosis after delayed treatment?}

There are relatively few data examining the effects of delayed treatment. Two retrospective studies showed that patients who had a longer duration of symptoms before treatment were more likely to have persistent subjective musculoskeletal and cognitive symptoms. However, there were no objective physical findings or neurocognitive 
testing abnormalities compared with uninfected controls $(78,79)$. Similar findings were reported in patients involved in studies of early Lyme disease, in which it was found that those who did not receive treatment on initial presentation with facial palsies were more likely to have body pain, physical limitations and a lower physical composite score on the SF36 (36 item Short-Form General Health Survey) compared with controls who received antibiotics at the time of presentation. They were also more likely to have mild neurocognitive symptoms, but their overall "mental composite" score on the SF-36 standardized form was not different from that of the control group (61).

\section{Can patients with Lyme disease have persistent symptoms after treatment?}

It is clear that a proportion of patients with confirmed evidence of previous Lyme disease continue to have symptoms after standard antimicrobial treatment. The terms "chronic Lyme disease" and "post-Lyme disease syndrome" have been applied by some clinicians to patients with symptoms persisting more than six months after treatment with the recommended agents. Persistent symptoms include fatigue, generalized musculoskeletal pain and cognitive impairment without objective findings or microbiological evidence of active infection.

Given that some patients have persistent symptoms after treatment of their Lyme disease, the question has been raised of whether there is benefit to prolonged antimicrobial therapy. Four randomized placebo controlled trials, all conducted in the US, have addressed this issue. The larger of the studies (80) included two separate studies (i.e. seropositive and seronegative studies) of patients clinically diagnosed with acute Lyme disease. Both studies enrolled patients who had previously been treated with a recommended antibiotic regimen and reported ongoing symptoms. The subjects were placed into the seropositive or seronegative study according to their serological status at the time of enrollment. There were 129 patients enrolled in the two studies, and participants were randomly assigned to receive either ceftriaxone $2 \mathrm{~g}$ daily for 30 days followed by doxycycline for 60 days, or placebo. Outcome measures included cognition, memory, pain and activities of daily living.

There were no differences between the treatment vs placebo groups in outcomes in either the seronegative or seropositive studies, and they were terminated early after an interim analysis by the Data and Safety Monitoring Board, on the basis that the studies would not be able to identify a difference between treatment vs placebo. A sub-study using data from this trial also found no differences between the treatment and control groups in mood and cognitive-related quality of life measures (81).

Krupp and colleagues compared $2 \mathrm{~g}$ daily of ceftriaxone for 28 days with placebo in 55 patients whose Lyme disease had been previously treated with a standard regimen (82). While the ceftriaxone group showed improvement in fatigue, there was no difference in cognition on formal testing. Three patients had intravenous line infections and one had anaphylaxis in reaction to ceftriaxone. Finally, 37 adults were randomly assigned to receive 10 weeks of ceftriaxone or placebo after completing treatment for Lyme disease (83). The patients who received ceftriaxone had non-sustained, mild improvements in cognition and a $26.1 \%$ adverse event rate versus $7.1 \%$ in the placebo group.

On the basis of these findings, the Infectious Diseases Society of America guideline does not recommend additional antimicrobial or prolonged treatment for patients who have completed a standard course of therapy for their Lyme disease (19). Any benefit that might be derived is small and not sustained, and has been associated with an excess risk of adverse events that may be life-threatening.

\section{How should Lyme disease in pregnancy be managed?}

While there have been reports of Lyme disease in pregnant women and sporadic case reports of transplacental transmission of $B$ burgdorferi, there is not a clear link between fetal infections and adverse outcomes $(84,85)$. Clinical, serological and epidemiological studies of Borrelia infection in pregnancy have failed to demonstrate an association between infection and adverse outcomes (84-86). Because doxycycline is contraindicated in pregnancy, treatment and prophylactic options are different than in the non-pregnant adult.

Some data suggest that a 10 day course of ampicillin may be an effective prophylactic strategy, although the risk of a rash developing in reaction to the beta lactam is greater than the risk of Lyme disease, and therefore the Infectious Diseases Society of America(IDSA) guideline does not recommend prophylaxis in the setting of 
pregnancy $(18,19,86)$. If an Ixodes tick bites a pregnant woman, she should be monitored for 30 days for signs and symptoms of Lyme disease and treated with amoxicillin or cefuroxime if it develops (19).

\section{Can individuals be re-infected with Borrelia burgdorferi?}

Relapses are recurrent symptoms that are the result of failure to cure the original infection, whereas re-infection is the recurrence of symptoms as a result of a new exposure to an infected tick, leading to a new infection. Although erythema migrans lesions can relapse if not treated with antibiotics (23), their recurrence after successful treatment is more likely to be re-infection than relapse (87).

Re-infection can occur in as many as $2 \%-21 \%$ of patients living in endemic areas who have had Lyme disease $(78,88-90)$. On examination, re-infection typically presents with an erythema migrans lesion at a different site than the original lesion more than 1-2.5 years after the original infection and not within 11 months of the first infection $(87,89,91)$. In one series, $79 \%$ of patients with re-infection presented with erythema migrans at a different site than the previous infection, and $21 \%$ presented with a febrile illness with myalgias. Re-infection after late Lyme disease characterized by arthritis or neuroborreliosis is very rare $(90,91)$.

Laboratory diagnosis of re-infection becomes a challenge, given that serology, including IgM, can remain positive for many years (92). Diagnosis is reliant on the clinical presentation of a new erythema migrans lesion at a different site. Recent data suggest that patients treated for re-infection have excellent outcomes. Patients with re-infection reported less fatigue than both the non-infected control group and patients with their first infection, suggesting that repeated infections present a lower risk of persistent symptoms (91).

\section{Conclusions}

Lyme disease is an emerging infection in Canada, and it is important that clinicians be aware of its epidemiology, clinical presentations and management. While sporadic cases of Lyme disease are possible from infected ticks that are imported on migrating birds, individuals living in or traveling to Lyme-endemic regions will be at greatest risk of infection. A thorough travel history is essential in a person presenting with symptoms suggestive of Lyme disease, particularly if symptoms compatible with one of the neurologic syndromes that are more common in Europe are present. It is important to inform the laboratory of a positive travel history, as the serologic testing for North American and European Borrelia strains is different.

Given the constantly expanding tick population it can be challenging to clearly define regions constituting the highest risk for Lyme disease, and it is important to remain abreast of local Lyme epidemiology through local public health.

\section{Conflict of interest}

The authors have no conflicts of interest to declare. 


\section{References}

(1) Kuehn, BM. CDC estimates 300000 US cases of Lyme diseaseannually. JAMA. 2013;310:1110

(2) Henry B, Roth D, Reilly R, MacDougall L, Mak S, Li M, et al. How big is the Lyme problem? Using novel methods to estimate the true number of Lyme diseasecases in British Columbia residents from 1997 to 2008. Vector Borne Zoonotic Dis. 2011;11:863-8.

(3) Owens B. Risk of tick-borne infections on the rise. CMAJ. 2013;185:E711.

(4) Ogden NH, Koffi, JK, Pelcat Y, Lindsay LR. Environmental risk from Lyme disease in central and eastern Canada: a summary of recent surveillance information. CCDR. 2014; 40:74-83

(5) Ogden NH, Lindsay LR, Morshed M, Sockett PN, Artsob H. The emergence of Lyme disease in Canada. CMAJ. 2009;180:1221-4.

(6) Lindsay LR, Bernat K, Dibernardo A. Laboratory diagnostics for Lyme disease. CCDR 2014;40:209-217

(7) Huegli D, Moret J, Rais O, Moosmann Y, Erard P, Malinverni R, et al. Prospective study on the incidence of infection by Borrelia burgdorferi sensu lato after a tick bite in a highly endemic area of Switzerland. Ticks Tick Borne Dis. 2011;2:129-36.

(8) Costello CM, Steere AC, Pinkerton RE, Feder HM Jr. A prospective study of tick bites in an endemic area for Lyme disease. J Infect Dis. 1989;159:136-9.

(9) Shapiro ED, Gerber MA, Holabird NB, Berg AT, Feder HM Jr, Bell GL, et al. A controlled trial of antimicrobial prophylaxis for Lyme disease after deer-tick bites. N Engl J Med 1992;327:1769-74.

(10) Agre F, Schwartz R. The value of early treatment of tick bites for the prevention of Lyme disease. Am J Dis Chilyme disease. 1993;147:945-7.

(11) Nadelman RB, Nowakowski J, Fish D, Falco RC, Freeman K, McKenna D, et al., Prophylaxis with single-dose doxycycline for the prevention of Lyme disease after an Ixodes scapularis tick bite. N Engl J Med. 2001;345:79-84.

(12) Sood SK, Salzman MB, Johnson BJB, Happ CM, Feig K, Carmody L, et al. Duration of tick attachment as a predictor of the risk of Lyme disease in an area in which Lyme disease is endemic. J Infect Dis. 1997;175:996-9.

(13) Pal U, Yang X, Chen M, Bockenstedt LK, Anderson JF, Flavell RA et al. OspC facilitates Borrelia burgdorferi invasion of Ixodes scapularis salivary glands. J Clin Invest. 2004;113:220-30.

(14) Piesman J, Zeidner NS, Schneider BS. Dynamic changes in Borrelia burgdorferi populations in Ixodes scapularis (Acari: Ixodidae) during transmission: studies at the mRNA level. Vector Borne Zoonotic Dis. 2003;3:125-32.

(15) Schwan TG, Piesman J. Temporal changes in outer surface proteins A and C of the Lyme disease-associated spirochete, Borrelia burgdorferi, during the chain of infection in ticks and mice. J Clin Microbiol. 2000;38:382-8.

(16) Radolf JD, Caimano MJ, Stevenson B, Hu LT. Of ticks, mice and men: understanding the dual-host lifestyle of Lyme diseases pirochaetes. Nat Rev Microbiol. 2012;10:87-99.

(17) Warshafsky S, Nowakowski J, Nadelman RB, Kamer RS, Peterson SJ, Wormser GP. Efficacy of antibiotic prophylaxis for prevention of Lyme disease. J Gen Intern Med. 1996;11:329-33.

(18) Warshafsky S, Lee DH, Francois LK, Nowakowski J, Nadelman RB, Wormser GP. Efficacy of antibiotic prophylaxis for the prevention of Lyme disease: an updated systematic review and meta-analysis. J Antimicrob Chemother. 2010;65:1137-44. 
(19) Wormser GP, Dattwyler RJ, Shapiro ED, Halperin JJ, Steere AC, Klempner MS, et al. The clinical assessment, treatment, and prevention of Lyme disease, human granulocytic anaplasmosis, and babesiosis: clinical practice guidelines by the Infectious Diseases Society of America. Clin Infect Dis. 2006 Nov 1;43:1089-134.

(20) Steere AC, Sikand VK, Schoen RT, Nowakowski J. Asymptomatic infection with Borrelia burgdorferi. Clin Infect Dis. 2003;37:528-32.

(21) Petersen LR, Sweeney AH, Checko PJ, Magnarelli LA, Mshar PA, Gunn RA, et al. Epidemiological and clinical features of 1,149 persons with Lyme disease identified by laboratory-based surveillance in Connecticut. Yale $\mathrm{J}$ of Biol Med 1989;62:253-62.

(22) Steere AC, Sikand VK. The presenting manifestations of Lyme disease and the outcomes of treatment. N Engl J Med. 2003;348:2472-74.

(23) Steere AC, Bartenhagen NH, Craft JE, Hutchinson GJ, Newman JH, Rahn DW, et al. The early clinical manifestations of Lyme disease. Ann Intern Med. 1983;99:76-82.

(24) Hengge UR, Tannapfel A, Tyring SK, Erbel R, Arendt G, Ruzicka T. Lyme borreliosis. Lancet Infect Dis. 2003;3:489-500.

(25) Nadelman RB, Luger SW, Frank E, Wisniewski M, Collins JJ, Wormser GP. Comparison of cefuroxime axetil and doxycycline in the treatment of early Lyme disease. Ann Intern Med. 1992;117:273-80.

(26) Luger SW, Paparone P, Wormser GP, Nadelman RB, GrunwaLyme diseaset E, Gomez G, et al. Comparison of cefuroxime axetil and doxycycline in treatment of patients with early Lyme disease associated with erythema migrans. Antimicrob Agents Chemother. 1995;39:661-7.

(27) Luft BJ, Dattwyler RJ, Johnson RC, Luger SW, Bosler EM, Rahn DW, et al. Azithromycin compared with amoxicillin in the treatment of erythema migrans. A double-blind, randomized, controlled trial. Ann Intern Med. 1996;124:785-91.

(28) Wormser GP, Ramanathan R, Nowakowski J, McKenna D, Holmgren D, Visintainer P, et al. Duration of antibiotic therapy for early Lyme disease. A randomized, double-blind, placebo-controlled trial. Ann Intern Med. 2003;138:697-704.

(29) Strle F, Maraspin V, Furlan-Lotric S, Cimperman J. Epidemiological study of a cohort of adult patients with Erythema migrans registered in Slovenia in 1993. Eur J Epidemiol. 1996;12:503-7.

(30) Weber K, Wilske B, Preac-Mursic V, Thurmayr R. Azithromycin versus penicillin V for the treatment of early Lyme borreliosis. Infection. 1993;21:367-72.

(31) Barsic B, Maretic T, Majerus L, Strugar J. Comparison of azithromycin and doxycycline in the treatment of erythema migrans. Infection. 2000;28:153-6.

(32) Kowalski TJ, Tata S, Berth W, Mathiason MA, Agger WA. Antibiotic treatment duration and long-term outcomes of patients with early Lyme disease from a Lyme disease-hyperendemic area. Clin Infect Dis. 2010;50:512-20.

(33) Dattwyler RJ, Luft BJ, Kunkel MJ, Finkel MF, Wormser GP, Rush TJ, et al. Ceftriaxone compared with doxycycline for the treatment of acute disseminated Lyme disease. N Engl J Med. 1997; 337:289-94.

(34) Gerber MA, Shapiro ED, Burke GS, Parcells VJ, Bell GL. Lyme disease in children in southeastern Connecticut. Pediatric Lyme disease Study Group. N Engl J Med. 1996;335:1270-4.

(35) Smith RP, Schoen RT, Rahn DW, Sikand VK, Nowakowski J, Parenti DL, et al. Clinical characteristics and treatment outcome of early Lyme disease in patients with microbiologically confirmed erythema migrans. Ann Intern Med. 2002;136:421-8

(36) Cerar D, Cerar T, Ruzić-Sabljić E, Wormser GP, Strle F. Subjective symptoms after treatment of early Lyme disease. Am J Med. 2010;123:79-86 
(37) Seltzer EG, Gerber MA, Cartter ML, Freudigman K, Shapiro ED. Long-term outcomes of persons with Lyme disease. JAMA. 2000;283:609-16.

(38) Steere AC. Lyme disease. N Engl J Med. 1989;321:586-96.

(39) Sigal LH. Early disseminated Lyme disease: cardiac manifestations. Am J Med. 1995;98:25S-28S.

(40) Centers for Disease Control and Prevention (CDC). Three sudden cardiac deaths associated with Lyme carditis - United States, November 2012-July 2013. MMWR Morb Mortal Wkly Rep. 2013;62:993-6.

(41) Bacon RM, Kugeler KJ, Mead PS; Centers for Disease Control and Prevention (CDC). Surveillance for Lyme disease--United States, 1992-2006. MMWR Surveill Summ. 2008;57:1-9.

(42) Logigian EL, Kaplan RF, Steere AC. Chronic neurologic manifestations of Lyme disease. N Engl J Med. 1990;323:1438-44.

(43) Clark JR, Carlson RD, Sasaki CT, Pachner AR, Steere AC. Facial paralysis in Lyme disease. Laryngoscope. 1985;95:1341-5.

(44) Kuiper H, Devriese PP, de Jongh BM, Vos K, Dankert J. Absence of Lyme borreliosis among patients with presumed Bell's palsy. Arch Neurol. 1992;49:940-3.

(45) Halperin JJ, Golightly M. Lyme borreliosis in Bell's palsy. Long Island Neuroborreliosis Collaborative Study Group. Neurology 1992;42:1268-70.

(46) Cook SP, Macartney KK, Rose CD, Hunt PG, Eppes SC, Reilly JS. Lyme disease and seventh nerve paralysis in children. Am J Otolaryngol. 1997;18:320-3.

(47) Nigrovic LE, Thompson AD, Fine AM, Kimia A. Clinical predictors of Lyme disease among children with a peripheral facial palsy at an emergency department in a Lyme disease-endemic area. Pediatrics. 2008;122:e1080-5.

(48) Eppes SC, Nelson DK, Lewis LL, Klein JD. Characterization of Lyme meningitis and comparison with viral meningitis in children. Pediatrics. 1999;103:957-60.

(49) Ljøstad U, Økstad S, Topstad T, Mygland A, Monstad P. Acute peripheral facial palsy in adults. J Neurol. 2005;252:672-6.

(50) Bremell D, Hagberg L. Clinical characteristics and cerebrospinal fluid parameters in patients with peripheral facial palsy caused by Lyme neuroborreliosis compared with facial palsy of unknown origin (Bell's palsy). BMC Infect Dis. 2011;11:215.

(51) Bremell D, Mattsson N, Wallin F, Henriksson J, Wall M, Blennow K, et al. Automated cerebrospinal fluid cell count - New reference ranges and evaluation of its clinical use in central nervous system infections. Clin Biochem. 2014;47:25-30.

(52) Avery RA, Frank G, Glutting JJ, Eppes SC. Prediction of Lyme meningitis in children from a Lyme diseaseendemic region: a logistic-regression model using history, physical, and laboratory findings. Pediatrics. 2006;117:e1-7.

(53) Cohn KA, Thompson AD, Shah SS, Hines EM, Lyons TW, Welsh EJ, et al. Validation of a clinical prediction rule to distinguish Lyme meningitis from aseptic meningitis. Pediatrics. 2012;129:e46-53.

(54) Garro AC, Rutman M, Simonsen K, Jaeger JL, Chapin K, Lockhart G. Prospective validation of a clinical prediction model for Lyme meningitis in children. Pediatrics. 2009;123:e829-34

(55) Vázquez M, Sparrow SS, Shapiro ED. Long-term neuropsychologic and health outcomes of children with facial nerve palsy attributable to Lyme disease. Pediatrics. 2003;112:e93-7. 
(56) Oksi J, Nikoskelainen J, Hiekkanen H, Lauhio A, Peltomaa M, Pitkäranta A, et al. Duration of antibiotic treatment in disseminated Lyme borreliosis: a double-blind, randomized, placebo-controlled, multicenter clinical study. Eur J Clin Microbiol Infect Dis. 2007;8:571-81.

(57) Pachner AR, Steiner I. Lyme neuroborreliosis: infection, immunity and inflammation. Lancet Neurol. 2007;6:544-552

(58) Steere AC, Schoen RT, Taylor E. The clinical evolution of Lyme arthritis. Ann Intern Med. 1987;107:725-31

(59) Tory HO, Zurakowski D, Sundel RP. Outcomes of chilyme diseaseren treated for Lyme arthritis: results of a large pediatric cohort. J Rheumatol. 2010;37:1049-55.

(60) Daikh BE, Emerson FE, Smith RP, Lucas FL, McCarthy CA. Lyme arthritis: a comparison of presentation, synovial fluid analysis, and treatment course in children and adults. Arthritis Care Res. 2013;65:1986-90.

(61) Kalish RA, Kaplan RF, Taylor E, Jones-Woodward L, Workman K, Steere AC. Evaluation of study patients with Lyme disease, 10-20-year follow-up. J Infect Dis. 2001;183:453-60.

(62) Thompson A, Mannix R, Bachur R. Acute pediatric monoarticular arthritis: distinguishing Lyme arthritis from other etiologies. Pediatrics. 2009;123:959-65.

(63) Milewski MD, Cruz AI Jr, Miller CP, Peterson AT, Smith BG. Lyme arthritis in children presenting with joint effusions. J Bone Joint Surg Am. 2011;93:252-60.

(64) Deanehan JK, Kimia AA, Tan Tanny SP, Milewski MD, Talusan PG, Smith BG, et al. Distinguishing Lyme from septic knee monoarthritis in Lyme disease-endemic areas. Pediatrics. 2013;131:e695-701.

(65) Steere AC, Levin RE, Molloy PJ, Kalish RA, Abraham JH 3rd, Liu NY, et al.. Treatment of Lyme arthritis. Arthritis Rheum. 1994;37:878-88.

(66) Li X, McHugh GA, Damle N, Sikand VK, Glickstein L, Steere AC. Burden and viability of Borrelia burgdorferi in skin and joints of patients with erythema migrans or Lyme arthritis. Arthritis Rheum. 2011;63:2238-47.

(67) Caperton EM, Heim-Duthoy KL, Matzke GR, Peterson PK, Johnson RC. Ceftriaxone therapy of chronic inflammatory arthritis. A double-blind placebo controlled trial. Arch Intern Med. 1990;150:1677-82.

(68) Steere AC, Green J, Schoen RT, Taylor E, Hutchinson GJ, Rahn DW, et al. Successful parenteral penicillin therapy of established Lyme arthritis. N Engl J Med. 1985;312:869-74.

(69) Dattwyler RJ, Wormser GP, Rush TJ, Finkel MF, Schoen RT, GrunwaLyme diseaset E, et al. A comparison of two treatment regimens of ceftriaxone in late Lyme disease. Wien Klin Wochenschr. 2005;117:393-7.

(70) Coyle PK, Schutzer SE. Neurologic aspects of Lyme disease. Med Clin North Am. 2002;86:261-84.

(71) Pfister HW, Preac-Mursic V, Wilske B, Einhäupl K. Cefotaxime vs penicillin G for acute neurologic manifestations in Lyme borreliosis. A prospective randomized study. Arch Neurol. 1989:46:1191-4.

(72) Kohlhepp W, Oschmann P, Mertens H-G. Treatment of Lyme borreliosis. Randomized comparison of doxycycline and penicillin G. J Neurol. 1989;236:464-9.

(73) Pfister H, Preac-Mursic V, Wilske B, Schielke E, Sörgel F, Einhäupl K. Randomized comparison of ceftriaxone and cefotaxime in Lyme neuroborreliosis. J Infect Dis. 1991:163:311-8.

(74) Karlsson M, Hammers-Berggren S, Lindquist L, Stiernstedt G, Svenungsson B. Comparison of intravenous penicillin $G$ and oral doxycycline for treatment of Lyme neuroborreliosis. Neurology. 1994:44:1203-7.

(75) Roháčová H, Hanči J, Hulinská D, Mailer H, Havlík J. Ceftriaxone in the treatment of Lyme neuroborreliosis. Infection. 1996;24:90-2.

(76) Borg R, Dotevall L, Hagberg L, Maraspin V, Lotric-Furlan S, Cimperman J, et al. Intravenous ceftriaxone compared with oral doxycycline for the treatment of Lyme neuroborreliosis. Scand J Infect Dis. 2005:37:44954. 
(77) Ljøstad U, Skogvoll E, Eikeland R, Midgard R, Skarpaas T, Berg A, et al. Oral doxycycline versus intravenous ceftriaxone for European Lyme neuroborreliosis: a multicentre, non-inferiority, double-blind, randomised trial. Lancet Neurol. 2008:7:690-95.

(78) Shadick NA, Phillips CB, Logigian EL, Steere AC, Kaplan RF, Berardi VP, et al. The long-term clinical outcomes of Lyme disease. A population-based retrospective cohort study. Ann Intern Med. 1994;121:560-7.

(79) Shadick NA, Phillips CB, Sangha O, Logigian EL, Kaplan RF, Wright EA, et al. Musculoskeletal and neurologic outcomes in patients with previously treated Lyme disease. Ann Intern Med. 1999;131:919-26.

(80) Klempner MS, Hu LT, Evans J, Schmid CH, Johnson GM, Trevino RP, et al. Two controlled trials of antibiotic treatment in patients with persistent symptoms and a history of Lyme disease.

N Engl J Med. 2001;345:85-92.

(81) Kaplan RF, Trevino RP, Johnson GM, Levy L, Dornbush R, Hu LT, et al. Cognitive function in post-treatment Lyme disease: do additional antibiotics help? Neurology. 2003;60:1916-22.

(82) Krupp LB, Hyman LG, Grimson R, Coyle PK, Melville P, Ahnn S, et al. Study and treatment of post Lyme disease(STOP-LYME DISEASE): a randomized double masked clinical trial. Neurology. 2003;60:1923-30.

(83) Fallon BA, Keilp JG, Corbera KM, Petkova E, Britton CB, Dwyer E, et al. A randomized, placebo-controlled trial of repeated IV antibiotic therapy for Lyme encephalopathy. Neurology. 2008;70:992-1003.

(84) Walsh CA, Mayer EW, Baxi LV. Lyme disease in pregnancy: case report and review of the literature. Obstet Gynecol Surv. 2007;62:41-50.

(85) Mylonas I. Borreliosis during pregnancy: a risk for the unborn children disease? Vector Borne Zoonotic Dis. 2011;11:891-8.

(86) Smith GN, Gemmill I, Moore KM. Management of tick bites and Lyme disease during pregnancy. J Obstet Gynaecol Can. 2012;34:1087-91.

(87) Nadelman RB, Hanincová K, Mukherjee P, Liveris D, Nowakowski J, McKenna D, et al. Differentiation of reinfection from relapse in recurrent Lyme disease. N Engl J Med. 2012;367:1883-90.

(88) Nowakowski J, Nadelman RB, Sell R, McKenna D, Cavaliere LF, Holmgren D, et al. Long-term follow-up of patients with culture-confirmed Lyme disease. Am J Med. 2003;115:91-6.

(89) Krause PJ, Foley DT, Burke GS, Christianson D, Closter L, Spielman A; Reinfection and relapse in early Lyme disease. Tick-Borne Disease Study Group. Am J Trop Med Hyg. 2006;75:1090-4.

(90) Nadelman RB, Wormser GP. Reinfection in patients with Lyme disease. Clin Infect Dis. 2007;45:1032-8.

(91) Jares TM, Mathiason MA, Kowalski TJ. Functional outcomes in patients with Borrelia burgdorferi reinfection. Ticks and tick-borne dis. 2014;5:58-62.

(92) Kalish RA, McHugh G, Granquist J, Shea B, Ruthazer R, Steere AC. Persistence of immunoglobulin M or immunoglobulin $\mathrm{G}$ antibody responses to Borrelia burgdorferi 10-20 years after active Lyme disease. Clin Infect Dis 2001;33:780-5. 